\title{
The influence of moisture content on shrinkage of wool fabrics during domestic tumble drying process
}

Wei Bao ${ }^{1,2,3}$, Jinsong Shen ${ }^{3}$, Xuemei Ding ${ }^{1,2,4^{*}}$

1. College of Fashion and Design, Donghua University, Shanghai, China;

2. Key Laboratory of Clothing Design \& Technology (Donghua University), Ministry of Education, Shanghai, China;

3. Textile Engineering and Materials (TEAM) Research Group, School of Fashion and Textiles, De Montfort University, Leicester, UK;

4. Shanghai International Institute of Design \& Innovation, Shanghai, China

* Corresponding author:

Xuemei Ding, College of Fashion and Design, Donghua University, Shanghai, China. Email: fddingxm@dhu.edu.cn

Present address: No.1882,West Yan-an Road, Shanghai, China

\section{Abstract}

Shrinkage of wool fabrics caused during tumble drying is a serious defect. In the drying process, the felting shrinkage of wool fabrics was influenced by the moisture content and temperature of wool fabric as well as mechanical action being applied on the wool fabric. In the current study, the relationship between moisture content of wool fabrics and shrinkage was studied in the drying programs under no heating condition or heated condition. This study also analyzed shrinkage behaviors of the untreated wool fabric and the Chlorine-Hercosett treated wool fabric with different moisture contents. For the untreated wool fabric, moisture content in the fabric could influence the mechanical properties of wool fibers, resulting in the different extent of felting shrinkage of wool fabric during tumble drying. For the Chlorine-Hercosett treated wool fabric at different initial moisture contents, there was no obvious variation in the length change under no heating condition, but a slight difference in the shrinkage under heated condition. The study could lead to the new guidance for efficient drying of wool fabric with less felting shrinkage.

\section{Key words}

Wool fabrics, shrinkage, felting, moisture, tumble drying 


\section{Introduction}

Domestic tumble dryers are popularly used for drying garments, especially during winter or bad weather conditions [1]. However, wool fabric shrinks easily in the process of tumble drying under heat, moisture and mechanical force. Usually shrinkage during tumble drying can be divided into three types [2, 3]: (1) dimensional change due to relaxation; (2) dimensional change which takes place when the moisture content of a relaxed fabric is altered; and (3) felting shrinkage due to the configuration of wool surface scales. In a normal tumble drying cycle, major shrinkage of untreated wool fabric was felting shrinkage [4]. It would be interesting to investigate the effect of moisture content of wool fabric on felting shrinkage of untreated wool fabric during tumble drying.

In the earlier work, McPhee and Wemyss et al. explored the extent of milling shrinkage as a function of varying quantities of water added to the solvent in the Launder-O-Meter or the solvent-based milling machine $[5,6]$. It was found that the shrinkage became significant in milling when the moisture content of wool exceeded $10 \%$, and then increased with the increase of water addition $[5,6]$. However, the medium in milling was solvent-water mixtures at ambient, which was different from the environment of tumble drying. The mechanical properties of wool fibers, such as rigidity [7-9], changed with the increase of moisture content in the fibers within $30 \%$, leading to the promotion of the felting shrinkage. Pierlot pointed out that felting shrinkage could be related to the glass transition temperature $\left(T_{g}\right)$ of wool fibers, because many mechanical properties of wool fibers were related to $T_{g}[10]$.

Wool felting is known to be influenced not only by mechanical properties of fibers, but also by surface properties of fibers. Many studies have been undertaken to investigate the effect of water on surface properties of wool fibers. There is a common agreement that "the wet wool fibers have greater difference in the coefficients of friction between against-scales $\left(\mu_{\mathrm{A}}\right)$ and with-scales $\left(\mu_{\mathrm{w}}\right)$ on the fiber surface, known as differential frictional effect (D.F.E.), than the dry wool fibers, and this was largely responsible for the felting behavior of wool" [11]. However, Frishman et al. showed that, the D.F.E. in the wet state of wool fibers was slightly lower than that in dry state [12]. This might be due to the use of the different measurement methods under different experimental conditions [11].

The current study investigated the relationship between moisture content of wool fabrics and shrinkage under room temperature and heated conditions in the tumble drying process. D.F.E. of the wool fibers and the moisture loss from various initial 
moisture contents were investigated to understand their influence on the felting shrinkage of wool. The Chlorine-Hercosett shrink-resist treated wool fabric was used for comparing to the untreated wool fabrics in the investigation of the effect of moisture content of wool fabric on shrinkage of wool fabric during tumble drying. The study could lead to the new guidance for efficient drying of wool fabric with less felting shrinkage in domestic tumble dryers.

\section{Experimental}

\subsection{Preparation of materials}

Wool fabrics used [4] were untreated and Chlorine-Hercosett treated wool fabrics made from $19.5 \mu \mathrm{m}$ merino wool. The scanning electron microscope images of untreated and treated wool fabrics are shown in Figure 1. The surface topography of untreated wool fibers shows well-defined edges of scales while Chlorine-Hercosett treated wools show a smooth surface due to the partial degradation of cuticle scales by chlorination and polymer surface coating [4]. Both fabrics were weft-knitted using 12 gauge flat knitting machine into plain fabrics with same knitting structure. The test samples of wool fabrics were prepared and made into double layers with a size of 300 $\mathrm{mm}$ x $400 \mathrm{~mm}$. The marked size for measurement of fabric dimension was $220 \mathrm{~mm} \times$ $300 \mathrm{~mm}$. According to Test Method - TWC - TM309 Performance of Domestic Tumble Driers for "Hand Wash" Wool Products, all fabric samples were relaxed by the relaxation procedure, i.e. being wet out in water at $40{ }^{\circ} \mathrm{C}$ for 30 minutes and then twice at $20{ }^{\circ} \mathrm{C}$ for 2 minutes followed by flat drying. After flat drying, the samples were conditioned at the standard atmosphere of $65( \pm 3) \% \mathrm{RH}$ and $20( \pm 2){ }^{\circ} \mathrm{C}$ for at least 24 hours [4].

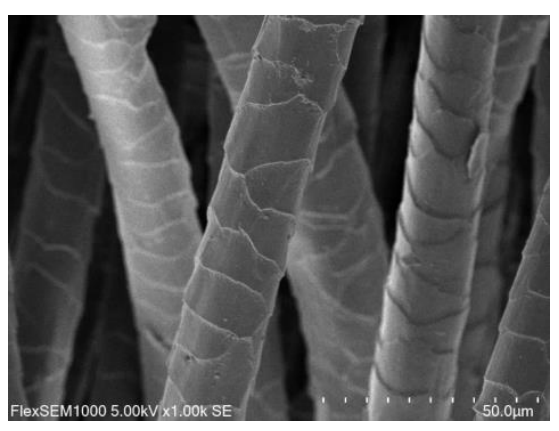

Untreated wool fabric $(\times 1000)$

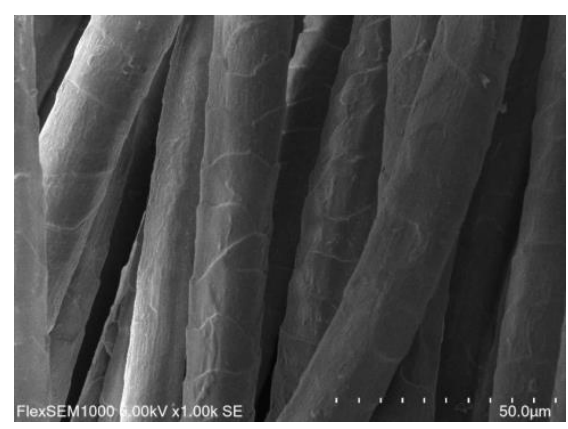

Treated wool fabric $(\times 1000)$

Figure 1 Scanning electron microscope images of untreated and Chlorine-Hercosett treated wool fabrics 
During the normal tumble drying process, temperature and moisture content of fabrics change simultaneously. In order to investigate the effect of moisture content on the dimensional change of wool fabrics, tumble drying of fabric samples with different initial moisture contents in the fabric was carried out under the room temperature (20 ${ }^{\circ} \mathrm{C}$ ) or the heated condition, as shown in Table 1 . The initial relative humidity of the environment was $60( \pm 7) \%$. The tumble dryer used in the study was a modified domestic thermoelectric air-vented dryer (GDZ10-977, Haier Co. Ltd, China) [4], in which the heater power, rotating speed of the drum and air flow velocity could be adjusted. Fabric load for tumble drying consisted of two untreated wool samples, two Chlorine-Hercosett treated wool samples and wool fabric ballast sufficient to make up to $2.0( \pm 0.01) \mathrm{kg}$ load. The initial moisture content in the fabric samples was controlled by spinning in a Haier top-load washer and flat drying [4].

Table 1 The tumble-drying programs

\begin{tabular}{ccccccc}
\hline & $\begin{array}{c}\text { Drying } \\
\text { testing No. }\end{array}$ & $\begin{array}{c}\text { Heater } \\
\text { power }(\mathrm{W})\end{array}$ & $\begin{array}{c}\text { Initial moisture } \\
\text { content }( \pm 2.5) \%\end{array}$ & $\begin{array}{c}\text { Rotating speed } \\
\text { of drum (rpm) }\end{array}$ & $\begin{array}{c}\text { Air flow } \\
\text { velocity }(\mathrm{m} / \mathrm{s})\end{array}$ & $\begin{array}{c}\text { Total time of } \\
\text { drying (min) }\end{array}$ \\
\hline Room & 1 & & 0 & & & \\
temperature & 3 & 0 & 5 & $50( \pm 2)$ & $5.5( \pm 0.5)$ & 70 \\
& 4 & & 30 & & & \\
\hline Under & 5 & & 60 & & & \\
heated & 6 & & 0 & $50( \pm 2)$ & $5.5( \pm 0.5)$ & 17.5 \\
condition & 7 & 4000 & 30 & & & \\
\hline
\end{tabular}

\subsection{Assessment of wool fabrics}

\subsubsection{Moisture content of wool fabric samples}

Moisture content of fabric was calculated using Equation (1) based on IEC 61121: 2012 "Tumble dryers for household use-Methods for measuring the performance".

$$
\mu_{\mathrm{t}}=\frac{W_{i}-W_{o}}{W_{o}} \times 100 \%
$$

Where $\mu_{\mathrm{t}}$ is moisture content of fabric, $w_{\mathrm{o}}$ is initial weight of fabric sample being at the standard atmosphere of $65 \% \mathrm{RH}$ and $20^{\circ} \mathrm{C}$ for 24 hours before washing and drying, $w \mathrm{i}$ is the weight of fabric samples after washing and drying [4]. 


\subsubsection{Relative Humidity $(\mathrm{RH})$ in the tumble dryer}

IButtons (DS 1923), being able to measure the range of Relative humidity (RH) from 0 to $100 \%$, were fixed on lifters in the tumble dryer to measure the relative humidity in the tumble drum during the tumble drying process. The relative humidity in the tumble drum was measured every 6 seconds for 17.5 min tumble drying under heated condition, or every 60 seconds for 70 min tumble drying under no heating condition.

\subsubsection{Temperature of fabric samples in the tumble dryer}

IButtons (DS 1922T), being able to measure the range of temperature from 0 to $125{ }^{\circ} \mathrm{C}$ with the resolution of $0.5^{\circ} \mathrm{C}$, were fixed in between two layers of fabric specimens to measure the temperature of the fabric during the tumble drying process [4]. The temperature of the fabric was measured every 6 seconds.

\subsubsection{Dimensional change of wool fabrics}

Length change of fabric samples was measured and calculated using Equation (2) according to AATCC Test Method 135 - 2014 "Dimensional Changes in Automatic Home Laundering of Woven or Knitted Fabrics".

$$
L C=\frac{B-A}{A} \times 100 \%
$$

Where $L C$ is length change of fabric sample in percentage, $A$ is original length of fabric sample before washing and drying, and $B$ is length after washing and drying. All of the fabric samples were measured after being conditioned at the standard atmosphere of $65 \% \mathrm{RH}$ and $20^{\circ} \mathrm{C}$ for at least 16 hours [4].

\subsubsection{Fiber frictional properties}

Frictional coefficients with-scale $\mu_{\mathrm{W}}$ and against-scale $\mu_{\mathrm{A}}$ of wool fibers were measured by the frictional coefficient tester of XCF-1A [13] (Shanghai New Fiber Instrument Co., Ltd, China). The principle of the measurement is to place the fiber around the roller, and apply the same tension to the two ends of the fiber. When the friction roller was rotated, the tension at one end of the fiber became smaller due to the differential friction of the fiber. The change of tension could be measured by the tension device, and the fiber friction coefficient was calculated according to Euler formula [13]. The Differential Frictional Effect (D.F.E., $\sigma=\mu_{\mathrm{A}}-\mu_{\mathrm{W}}$ ) was determined and used to compare the difference in frictional properties between untreated dry wool fibers and 
wet wool fibers.

The moisture content of wet wool fibers was controlled around $78 \%$ after spinning in a washing machine. Before measurement, these wet fibers were sealed into a small hermetic bag to avoid water loss. The dry wool fibers were conditioned in the standard atmosphere of $65 \% \mathrm{RH}$ and $20{ }^{\circ} \mathrm{C}$ for at least $24 \mathrm{~h}$. Frictional coefficients of 13 dry wool fibers and 13 wet wool fibers were measured.

\section{Results and discussion}

3.1 Moisture loss of wool fabrics at different initial moisture contents during tumble drying process

The initial moisture contents of wool fabrics before tumble drying were controlled at the various levels of $0 \%, 5 \%, 15 \%, 30 \%$ and $60 \%$. The moisture loss of the untreated wool fabric and the Chlorine-Hercosett treated wool fabric from the different initial moisture contents through tumble drying under no heating condition for 70 min was measured as shown in Figure 2. It shows that there was no significant difference in moisture loss between the untreated wool fabric and the Chlorine-Hercosett treated wool fabric. The rate of moisture loss increased with increasing initial moisture content within around $30 \%$, but the rate of moisture loss decreased when the moisture content increased further to $60 \%$. Based on dividing the range of the moisture content of wool fabrics into two parts using "the critical moisture content", the reasons were analyzed as follows.

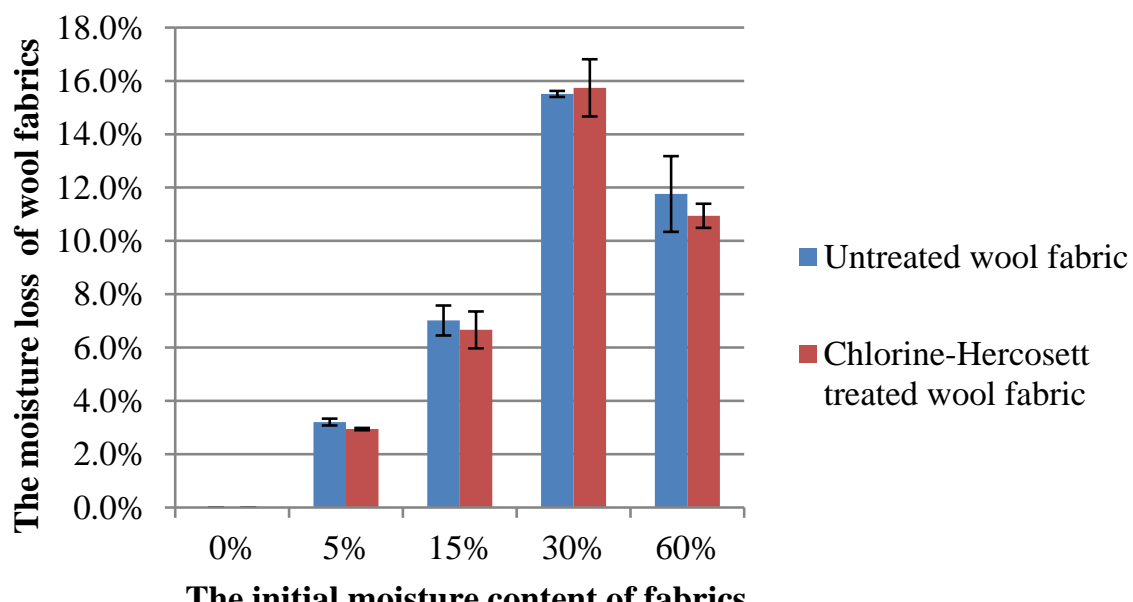

The initial moisture content of fabrics

Figure 2 Moisture loss of wool fabrics from different initial moisture content during tumble drying at $20^{\circ} \mathrm{C}$ for $70 \mathrm{~min}$. Error bars indicate the standard deviation of two repeated experiments

The critical moisture content is the average moisture content at which the drying 
rate begins to decline in a process of drying [14]. It could be approximately equivalent to the moisture regain of the wool at equilibrium in the atmosphere of $100 \%$ relative humidity $[14,15]$. When the moisture content was lower than the critical moisture content, the rate of moisture loss of wool fabric increased with the increase of the moisture content, probably due to the increase in mobility of water in the wool fiber, which means that the bonding between water and the molecular chain of fiber become less stable $[16,17]$. When the moisture content was higher than the critical moisture content, the rate of moisture loss might be mainly related to: (1) the difference between the vapor pressure of water at the fabric surface $\left(\mathrm{P}_{\mathrm{s}}\right)$ and the partial pressure of water in the air $\left(\mathrm{P}_{\mathrm{a}}\right)$, and (2) the surface area of fabrics that contact with the air [18]. When the moisture content in the wool fabric was $60 \%$, the vapor pressure of water in the air around fabric in the tumble drum at around $20^{\circ} \mathrm{C}$ may be close to saturation. As shown in Figure 4 (a), when it was $60 \%$ the relative humidity in the tumble dryer exceeded $95 \%$ during tumble drying under no heating condition. The difference between the vapor pressure of water at the surface and the partial pressure of water in the air at $60 \%$ moisture content of fabric may be lower than that at $30 \%$, so the moisture loss at the moisture content of $30 \%$ was higher than that at $60 \%$. Another possible reason was that the load of fabrics containing moisture content of $60 \%$ was higher than that containing $30 \%$, so that the fabric movements during tumble rotating may be different, resulting in different areas of fabric being contacted with the air.

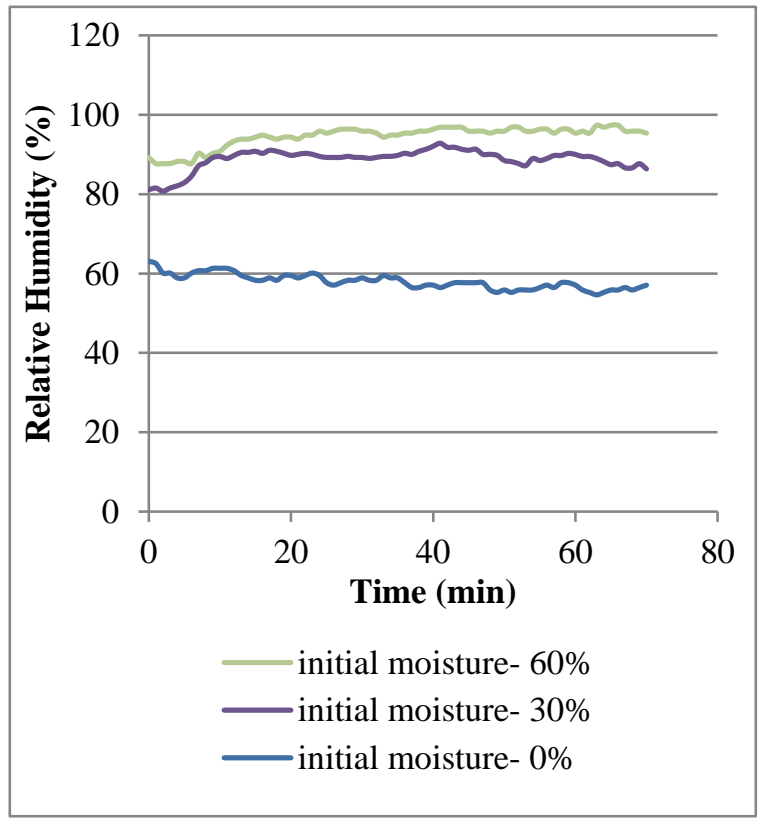

(a) Under no heating condition

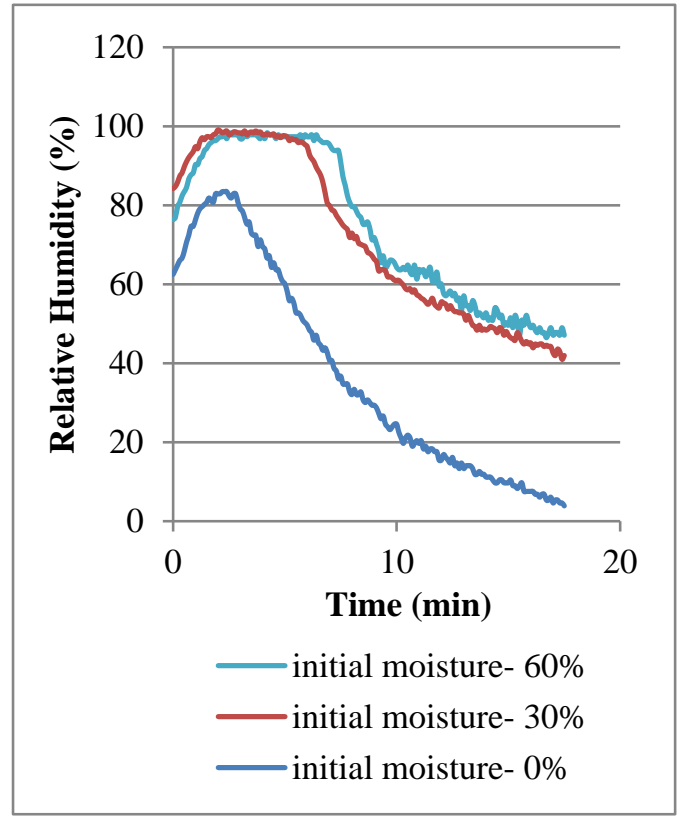

(b) Under heated condition

Figure 4 Relative Humidity (RH) in the tumble dryer during tumble drying: (a) under no heating condition, and (b) under heated condition 
Under heated condition in the tumble drying machine, the moisture of fabric decreased quickly with drying time. Figure 3 shows the moisture loss of the untreated wool fabric and the Chlorine-Hercosett treated wool fabric from different initial moisture contents through tumble drying under heated condition for $17.5 \mathrm{~min}$. The moisture loss of fabrics increased with the increase of initial moisture content under heated condition. It was found that the rate of moisture loss of wool fabrics containing initial moisture content of $60 \%$ was higher than that containing $30 \%$, which was different to the results under no heating drying condition (Figure 2). This may be because with the increase of temperature under heating, the vapor pressure of water in the air around fabric in the tumble drum at $60 \%$ moisture content may be not close to saturation during tumble drying. As shown in Figure 4 (b), when the moisture content of the wool fabrics was $60 \%$, the relative humidity in the tumble dryer decreased rapidly after around $7 \mathrm{~min}$ during tumble drying under heated condition. The difference between the vapor pressure of water at the drying surface $\left(\mathrm{P}_{\mathrm{s}}\right)$ and the partial pressure of water in the air $\left(\mathrm{P}_{\mathrm{a}}\right)$ at the moisture content of $60 \%$ may be higher than that containing $30 \%$. Therefore, moisture liberation of wool fabric containing moisture content of $60 \%$ was higher than that containing $30 \%$.

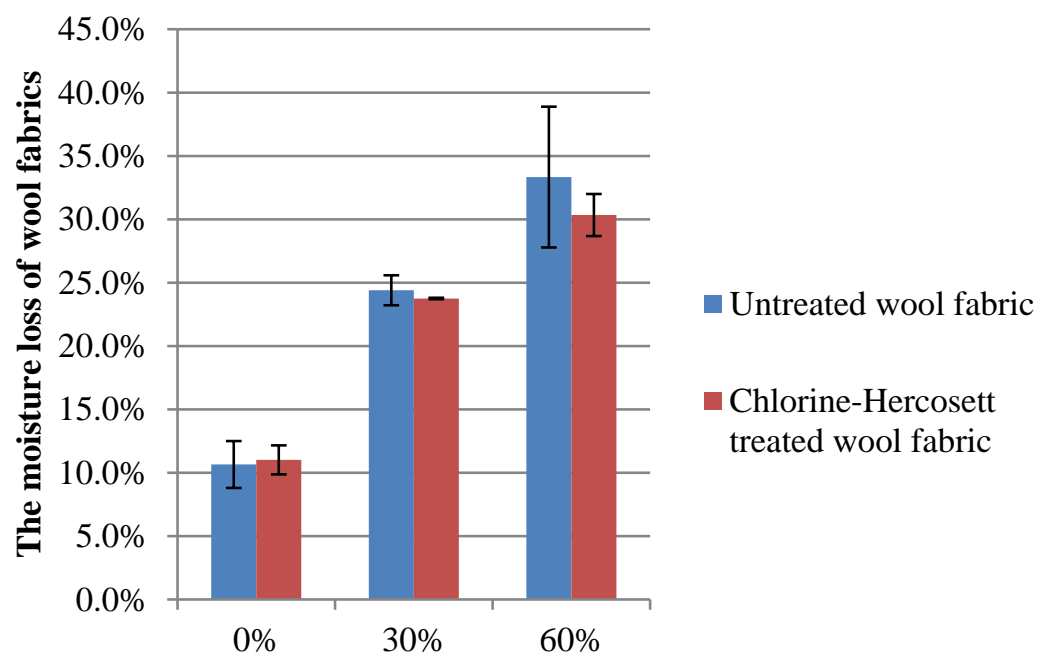

The initial moisture content of fabrics

Figure 3 Moisture loss of wool fabrics from different initial moisture content during tumble drying under heated condition for $17.5 \mathrm{~min}$. Error bars indicate the standard deviation of two repeated experiments

3.2 Effect of initial moisture contents on the shrinkages of wool fabrics during the tumble drying at room temperature 
In the drying process, the felting shrinkage is influenced by the moisture, temperature and mechanical action. In order to understand the effect of moisture content of fabrics on the felting shrinkage, the temperature was controlled at $20( \pm 3){ }^{\circ} \mathrm{C}$ and the rotation speed of the tumble drying drum was kept constant at $50 \mathrm{rpm}$. Figure 5 shows the length changes of the untreated and the Chlorine-Hercosett treated wool fabrics with different initial moisture contents after tumble drying at $20{ }^{\circ} \mathrm{C}$ for $70 \mathrm{~min}$. For the Chlorine-Hercosett treated wool fabric, there was no obvious variation in the length change at different initial moisture contents. While for the untreated wool fabric, the shrinkage in the fabric length increased rapidly with increasing initial moisture content of fabric when initial moisture content was within $15 \%$, but when the initial moisture content was more than $15 \%$, the length shrinkage of wool fabric increased slightly and leveled off.

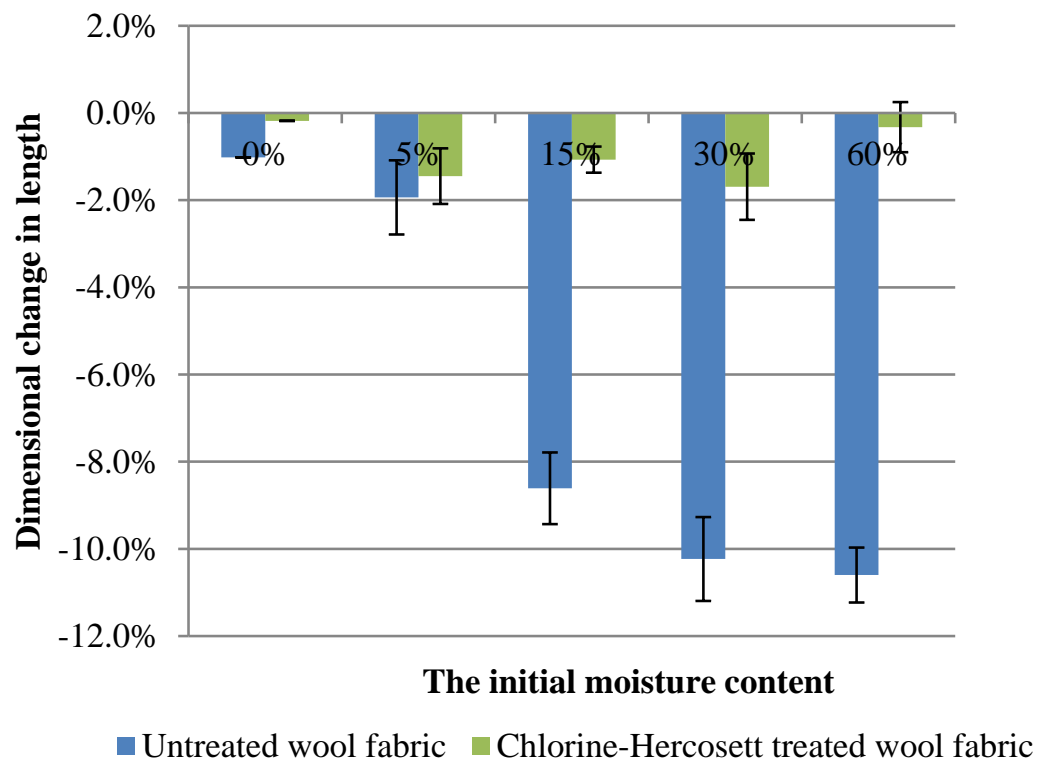

Figure 5 Length change of fabrics at different initial moisture content at $20^{\circ} \mathrm{C}$ during tumble drying for $70 \mathrm{~min}$. Error bars indicate the standard deviation of two repeated experiments

The moisture content of fabric determined in the current study is the ratio of the mass of water to mass of wool fabric that was conditioned at the standard atmosphere $\left(20{ }^{\circ} \mathrm{C}, 65 \% \mathrm{RH}\right)$. Therefore, when the moisture content of wool fabric is 0 , the wool fabric is not absolute dry but contain the certain amount of moisture as called the moisture regain [19]. The moisture regain of the untreated wool is the ratio of the mass of water in wool fiber to mass of absolute dry wool [19]. The moisture regain of wool at the temperature of $20^{\circ} \mathrm{C}$ and relative humidity of $65 \%$ was around $15 \%$ [19]. 
When the initial moisture content of wool fabric was $15 \%$, the absolute moisture amount in wool fibers (i.e. moisture regain of wool fibers), which was calculated assuming all the water resided in the wool, should be around $30 \%$. When the moisture regain of wool was within $30 \%$, the mechanical properties of wool fibers changed with the increase of moisture regain. For example, the bending rigidity [9] decreased, and the recovery [20] of a wool fiber increased. When the moisture regain was more than $30 \%$, the mechanical properties of wool fibers changed slightly [7]. Compared with the literature [9] on the mechanical properties varying with different moisture regains, it can be found that the trends that felting shrinkage varied and bending rigidity [9] varied with different moisture contents were similar. To some degree, this could be explained by the mechanism of wool felting proposed by Shorter, which is "in one case, casual disturbances will increase the length of the fiber between the two entanglements causing loops to form in the fiber" [21]. There is no doubt that the cause of "loop" is closely related to the mechanical properties. Therefore, to a large extent, the difference of mechanical properties, such as bending rigidity, was responsible for various severities of felting shrinkage of untreated wool fabric with different moisture contents.

Apart from the mechanical properties of wool fibers, felting is also influenced by surface properties of wool fibers. Wool has a unique differential frictional effect (D.F.E.) due to the configuration of the cuticle scales on the surface of wool fiber. "A common agreement" [11] was that the greater difference in the coefficients ( $\mu_{\mathrm{A}}$ and $\left.\mu_{\mathrm{W}}\right)$ of wet friction was largely responsible for the felting behavior of wool. However, the comparison results of D.F.E. between dry and wet wool fibers in the previous literatures are controversial. Many previous studies reported that the D.F.E. of wet wool fibers was higher than that of dry fibers [22-27]. However, Frishman et al. (1948) [12] measured the coefficients of friction of wool fibers at both wet and dry conditions. It was found that the D.F.E. in the wet state was slightly lower than that in the dry state [12]. It should be noted that the surface friction of wool fibers was usually measured in distilled water $[12,27,28]$, so the result may not be applied to wool fibers in the drying process without aqueous environment. In this study, the frictional coefficient of wet fibers was measured in the air. The results are shown in Table 2. The average differential frictional effects (D.F.E.) of dry fibers and wet fibers were 0.020 and 0.007 respectively. The T-test showed $\mathrm{P}=6.27 \times 10^{-5}<0.05$, so D.F.E. of wet fibers was lower than that of dry fibers, which was different to the results from the most previous studies. This might be due to the different test machines and environments used. Water on the fibers may act as a lubricant $[29,30]$; the scales may also stand out further from the swollen wet fibers than 
from dry fibers [21, 27]. It was complicated and unclear about the effect of dry and wet surface properties on the felting shrinkage of the untreated wool fabric. In any case, the change of mechanical properties of fibers plays an important role in the change of felting shrinkage at different moisture content. This is supported by some previous studies, which stated that "dry wool will not felt due to insufficient flexibility of wool fibers or their rigidity" [21].

Table 2 Frictional coefficients of dry and wet wool fibers

\begin{tabular}{|c|c|c|c|c|c|c|c|}
\hline \multirow{2}{*}{$\begin{array}{c}\text { Dry } \\
\text { Number }\end{array}$} & \multicolumn{7}{|c|}{ Wet } \\
\hline & $\mu_{\mathrm{W}}$ & $\mu_{\mathrm{A}}$ & $\sigma$ & Number & $\mu_{\mathrm{W}}$ & $\mu_{\mathrm{A}}$ & $\sigma$ \\
\hline 1 & 0.2259 & 0.2436 & 0.0177 & 1 & 0.2746 & 0.2802 & 0.0056 \\
\hline 2 & 0.2269 & 0.2453 & 0.0184 & 2 & 0.2656 & 0.2808 & 0.0152 \\
\hline 3 & 0.2333 & 0.2458 & 0.0125 & 3 & 0.2582 & 0.2693 & 0.0111 \\
\hline 4 & 0.2134 & 0.2220 & 0.0086 & 4 & 0.2540 & 0.2619 & 0.0079 \\
\hline 5 & 0.2152 & 0.2425 & 0.0273 & 5 & 0.2371 & 0.2403 & 0.0032 \\
\hline 6 & 0.2047 & 0.2268 & 0.0221 & 6 & 0.2665 & 0.2700 & 0.0035 \\
\hline 7 & 0.2253 & 0.2311 & 0.0058 & 7 & 0.2400 & 0.2418 & 0.0018 \\
\hline 8 & 0.1967 & 0.2331 & 0.0364 & 8 & 0.2376 & 0.2465 & 0.0089 \\
\hline 9 & 0.2154 & 0.2324 & 0.0170 & 9 & 0.2302 & 0.2333 & 0.0031 \\
\hline 10 & 0.2100 & 0.2381 & 0.0281 & 10 & 0.2248 & 0.2397 & 0.0149 \\
\hline 11 & 0.2077 & 0.2319 & 0.0242 & 11 & 0.2277 & 0.2303 & 0.0026 \\
\hline 12 & 0.2081 & 0.2263 & 0.0182 & 12 & 0.2384 & 0.2411 & 0.0027 \\
\hline 13 & 0.2208 & 0.2476 & 0.0268 & 13 & 0.2261 & 0.2381 & 0.0120 \\
\hline Average & 0.2156 & 0.2359 & 0.0202 & Average & 0.2447 & 0.2518 & 0.0071 \\
\hline $\begin{array}{l}\text { Standard } \\
\text { Deviation }\end{array}$ & 0.0100 & 0.0081 & 0.0081 & $\begin{array}{l}\text { Standard } \\
\text { Deviation }\end{array}$ & 0.0164 & 0.0173 & 0.0047 \\
\hline
\end{tabular}

Notes: $\mu_{\mathrm{W}}=$ frictional coefficiency of fibers with scale; $\mu_{\mathrm{A}}=$ frictional coefficiency of fibers against scale; $\sigma=\mu_{\mathrm{A}}-\mu_{\mathrm{W}}$

The initial water content of wet fibers is approximately $78 \%$.

3.3 Shrinkages of fabrics at different initial moisture contents under heated condition Under heated condition, both moisture content (Figure 3) and temperature (Figure 6) of wool fabrics changed in the duration of drying. Figure 6 shows the change in the temperature of untreated wool fabrics at different initial moisture contents during the time of drying under heated condition. When the initial moisture content in the wool fabric was $0 \%$, the temperature of fabric increased steadily with time until around 13 min and then maintained due to the overheat protection of the dryer. When the initial moisture contents of the fabrics were at $30 \%$ and $60 \%$, fabric temperatures changed in the similar trend. Usually the fabric drying process can be divided into three stages [4], but it could only be divided into two stages in this case due to the limited drying time 
(Figure 6). The temperature of wool fabric increased rapidly (first stage) in the first 5 minutes of drying followed by a slow rise (second stage). The fabric temperature for $30 \%$ initial moisture content was slightly higher than that for $60 \%$ initial water content in the second stage of tumble drying.

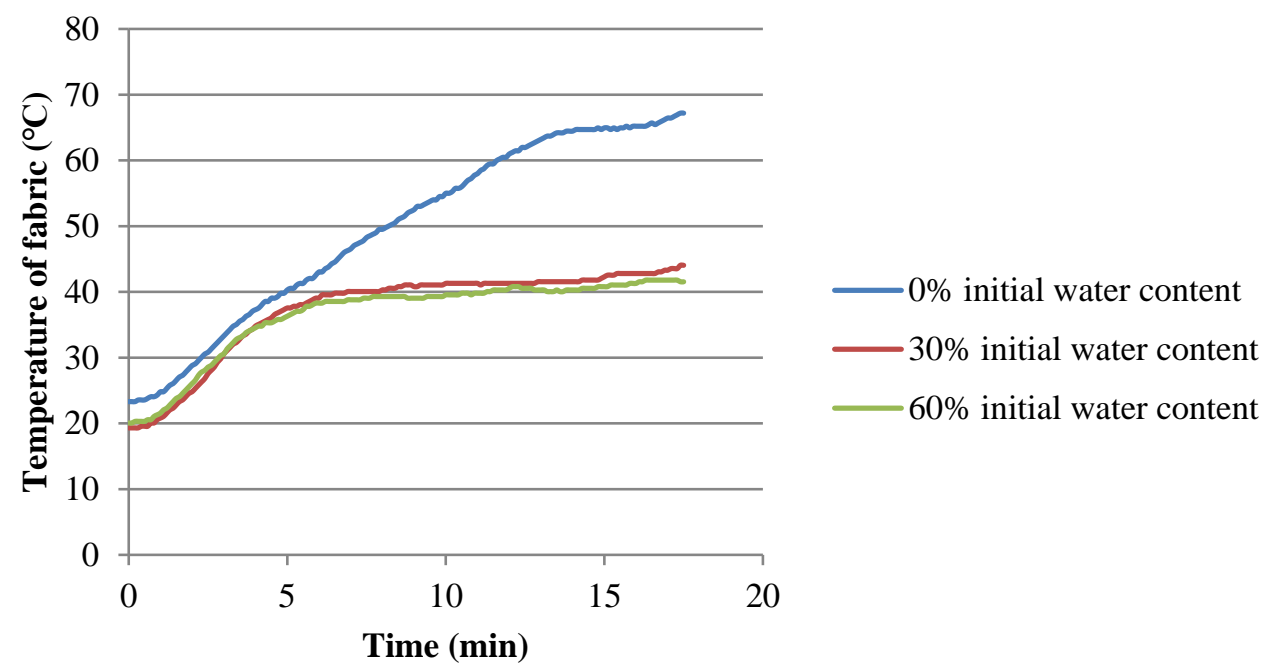

Figure 6 Temperature of untreated wool fabrics at different initial moisture content during tumble drying under heated condition

Figure 7 shows the change in the length of the untreated wool fabric and ChlorineHercosett treated wool fabric with different initial moisture contents during tumble drying process under heated condition for $17.5 \mathrm{~min}$. The trend of shrinkage in the length of untreated wool fabric with increasing initial moisture content was different from that of Chlorine-Hercosett treated wool fabric. Based on the previous related studies [4, 31] and the comparison of severities of shrinkage between untreated wool fabric and Chlorine-Hercosett treated wool fabric, the reasons that caused the different shrinkage of wool fabrics at different initial moisture contents were discussed as follows. When the initial moisture content of fabric was $60 \%$, with the moisture content of wool fabric decreased to around 30\% during tumble drying, the Chlorine-Hercosett treated wool fabric did not shrink basically, but the shrinkage of the untreated wool fabric occurred probably due to D.F.E. [4]. When the initial moisture content of fabric was approximately $30 \%$, the fibers deswelled causing voids to appear between fibers [32]. The shrinkage of the Chlorine-Hercosett treated wool fabric at this stage was caused by the agitation that could overcome inter-fiber and inter-yarn adhesions and allowing yarn diameters to contract when the water was removed from fabric [4, 31]. As for untreated wool fabric, the shrinkage in $30 \%$ initial moisture content was slightly higher than that 
in $60 \%$. When the initial moisture content was $30 \%$, apart from felting, the agitation and removed water allowing the yarn diameter to contract, maybe also contribute to the shrinkage of the untreated wool fabric. When the initial moisture content of fabric was $0 \%$, there was no significant difference in the dimensional change of wool fabrics between the untreated wool fabric and the Chlorine-Hercosett treated wool fabric. The shrinkage of wool fabrics might be due to the change of fiber shape, such as tiny crimps [33], caused by the moisture loss and increased temperature.

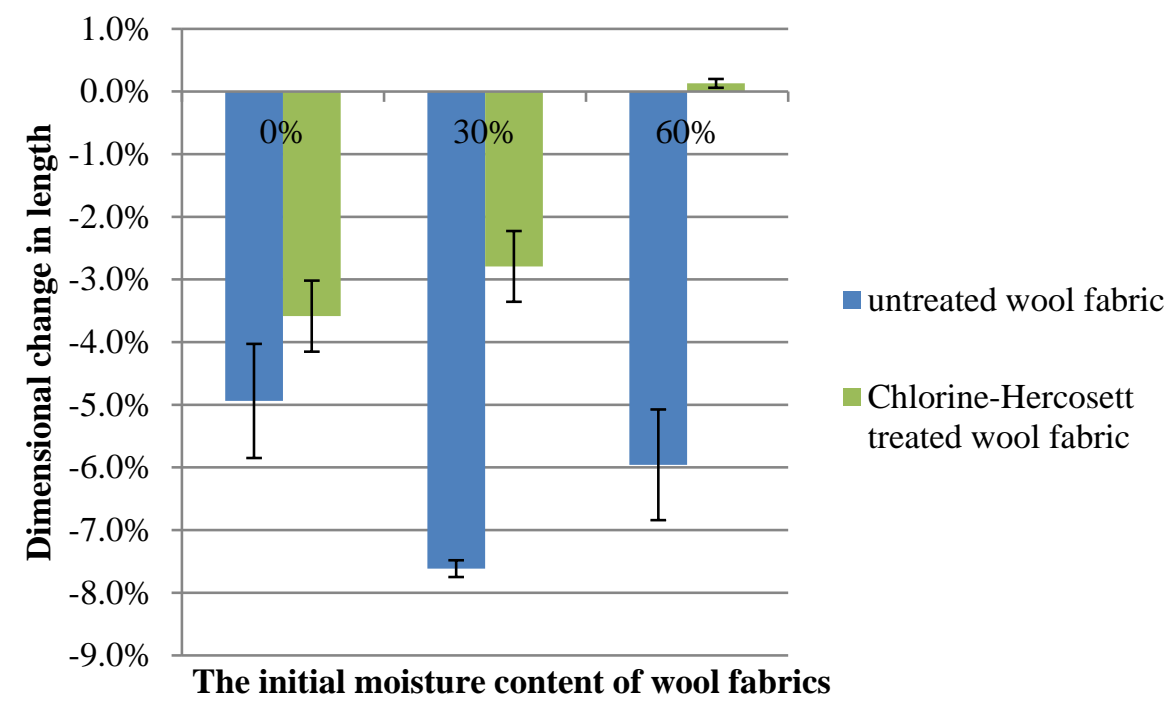

Figure 7 Length change of fabrics in different initial moisture content under heated condition for 17.5 min. Error bars indicate the standard deviation of two repeated experiments

\section{Conclusions}

In the drying process, the felting shrinkage was influenced by the moisture content of fabric, temperature of fabric and mechanical action being applied on the fabric. The current study investigated the relationship between moisture content and shrinkage of wool fabrics under no heating and heated condition in the tumble dryer.

Without heating, there was no obvious influence of the initial moisture content on the shrinkage of the Chlorine-Hercosett treated wool fabric. However, the shrinkage of untreated wool fabric increased rapidly with increasing moisture content up to $15 \%$ in the fabric, and then there was no significant further increase in the shrinkage of untreated wool fabric when the moisture content in the fabric was more than $15 \%$. The results of frictional coefficients of dry fibers and wet fibers showed that the D.F.E. of the wet wool fibers was slightly lower than that of dry wool fibers, which was different from the most previous studies, maybe due to different experimental conditions and 
different test methods. It was not clear of the effect of surface property change at different moisture contents on the felting shrinkage of the untreated wool fabric. It is obvious that the change of mechanical properties of fibers played an important role in felting shrinkage change at different moisture contents. Under heated condition, the reasons of the shrinkage of wool fabrics with different moisture contents may be various.

This study could give guidance for the care of wool fabrics to avoid shrinkage in tumble drying process. In the normal mechanical action of the tumble dryer, with more than 5\% moisture content, the felting shrinkage will occur for the untreated wool fabric in the drying process. Therefore, the initial moisture content of wool fabric to be tumble dried should be as low as possible, and it is necessary to change the mechanical action to avoid felting shrinkage of the untreated wool fabric for the duration of tumble drying. The effect of mechanical action on felting shrinkage of the untreated wool fabric will be further studied.

\section{Acknowledgements}

The funding supports to this research are provided by The Fundamental Research Funds for the Central Universities (Grant NO. 2232020G-08), National Key R\&D Program of China through project 2019YFB1706304, Shanghai Science and Technology Committee through project 17DZ2202900, Shanghai Summit Discipline in Design through project DD18005, the Institute for Nonlinear Sciences of Donghua University through project INS1901, and the China Scholarship Council.

\section{References}

1. K. Laitala, I. G. Klepp, and B. Henry, Use phase of apparel: A literature review for Life Cycle Assessment with focus on wool. Report, Consumption Research Norway, Oslo and Akershus University College of Applied Sciences. Report no. 6-2017, 2017.

2. M. Cednäs, J. Text. I. Trans., 52, T251 (1961).

3. Textile Technology Overseas, 2, 23 (1976).

4. W. Bao, J. Shen, X. Ding, and X. Wu, Text. Res. J., 89, 4702 (2019).

5. A. M. Wemyss, MSc Thesis, Deakin University, Australia, 1979.

6. J. McPhee and J. Preston, Text. Res. J., 36, 1101 (1966).

7. R. Meredith, J. Text. I. Trans., 48, T163 (1957). 
8. B. Mackay, and J. Downes, J. Appl. Polym. Sci., 2, 32 (1959).

9. B. Chapman, J. Text. I., 64, 312 (1973).

10. A. P. Pierlot, Text. Res. J., 67, 616 (1997).

11. J. Rippon, “Friction in textile materials”, pp. 253-291, Woodhead Publishing, Cambridge, 2008.

12. D. Frishman, A.L. Smith, and M. Harris, Text. Res. J., 18, 475 (1948).

13. R. Li, X. Huang, R. Zhang, W. Yu, C. Shen, S. Sun, G. Xu, F. Ji, Z. Ling, L. Wu, and F. Huang, A fiber friction coefficient testing device and testing method. CN Parent, 104849208 (2017).

14. L. Fourt, A. M. Sookne, D. Frishman, and M. Harris, Text. Res. J., 21, 26 (1951).

15. J. Preston, and J. Chen, J. Soc. Dyers and Colourists, 62, 361 (1946).

16. M. Feughelman, and A. Haly, Text. Res. J., 32, 227 (1962).

17. M. Feughelman, "Mechanical properties and structure of alpha-keratin fibres: wool, human hair and related fibres", University of New South Wales Press, Sydney, 1997.

18. K. Gurudatt, V. M. Nadkarni, and K. C. Khilar, J. Text. I., 101, 635 (2010).

19. A. P. Pierlot, Text. Res. J., 69, 97 (1999).

20. A. Haly, and M. Feughelman, Text. Res. J., 31, 135 (1961).

21. R. W. Moncrieff, "Wool shrinkage and its prevention”, The National Trade Press, London, 1953.

22. G. Flanagan, Felting and ratchet action of wool fibers. Text. Res. J., 36, 55, (1966).

23. A. Martin, J. Soc. Dyers and Colourists, 60 , 325 (1944).

24. E. H. Mercer, Journal of the Council for Scientific and Industrial Research, 18 (188) 1945.

25. A. F. Ham, D. E. Jones, Wear, 4, 198 (1961).

26. L. Bohm, Soc. Dyers and Colourists, 61, 278 (1945).

27. J. B. Speakman, E. Stott, and H. Chang, J. Text. I. Trans., 24, T273 (1933).

28. A. Van der Vegt and G. Schuringa, Text. Res. J., 26, 9, 1956.

29. X. Liu, and X. Wang, Text. Res. J., 77, 957, (2007).

30. M. C. Chen, T. Ree, and H. Eyring, Text. Res. J., 22, 416 (1952).

31. L. Higgins, S. C. Anand, M. E. Hall, and D. A. Holmes, J. Text. I., 94, 129 (2003).

32. L. Higgins, S. C. Anand, M. E. Hall, and D. A. Holmes, Int. J. Cloth. Sci. Tech.,15, 126 (2003).

33. Knitting Industries, (02), 36, (1977) 